\title{
“Donate your organs, donate life!" Explicitness in policy instruments
}

\author{
Eva Thomann ${ }^{1}$ iD
}

Published online: 14 June 2018

(C) The Author(s) 2018

\begin{abstract}
Behavioural research suggests that the intensity with which policy instruments indicate a direction of desired behavioural change affects how target populations respond to them. However, comparative research on policy instruments focuses on their calibration, restrictiveness, density and formal intensity, but does not account for the degree to which they specify the particular policy goal. Moving beyond nudging and "command and control" approaches, this paper adds the dimension of explicitness to existing taxonomies of policy instruments. The explicitness of an instrument results from two questions: first, does the instrument specify a direction of behavioural change? Second, does the instrument attach valence to this behaviour? The paper proposes a stepwise measurement procedure and links explicitness with policy outcomes. A comparative case study of organ donor policy in Switzerland and Spain illustrates how accounting for the explicitness dimension can improve our understanding of policy instruments and their effectiveness.
\end{abstract}

Keywords Behavioural public policy · Explicitness · Policy design · Policy instruments · Organ donation

\section{Problems, power and policy instruments}

It is wise and prudent for policy makers to be much more careful about understanding the behavioural aspects of both policy tools and targets and ensure these match up in an effective compliance regime.

M. Howlett (2016, p. 21).

Policy instruments communicate messages about overarching policy objectives to target groups. Scholarly interest in the messages to citizens engrained in public policies is

Eva Thomann

e.thomann@exeter.ac.uk

1 Department of Politics, University of Exeter, Amory Building, Rennes Drive, Exeter EX4 4RJ, UK 
increasing (Shafir 2013; Thaler and Sunstein 2008). Policy tools have an informational component that affects how they work in practice (John 2016). Scholars of responsive regulation, behavioural public policy and administration point to the huge potential of behaviourally informed intervention as effective intervention strategies (Alemanno and Sibony 2015; Ayres and Braithwaite 1992; Grimmelikhuijsen et al. 2017; Oliver 2013). Surprisingly, however, this insight has not yet made its way into the comparative study of policy instruments. Although compliance with public policies is a key concern, we know surprisingly little about the precise link between policy instruments and outcomes (e.g. Gofen 2015; Knill et al. 2012; see Schaffrin et al. 2015 and Weaver 2014 for recent overviews). To improve our understanding of regulatory effectiveness, this paper adds the dimension of explicitness to existing taxonomies of properties of policy instruments. It illustrates different levels of explicitness and their link with policy outcomes using the case of organ donation regulation.

Policy instruments are a set of techniques used by public actors to ensure support and to either effect or prevent social change (Vedung 1998: 21). "Policy instruments" and "policy output" are closely intertwined concepts. I follow Schaffrin et al. (2015: 258) who "take a perspective where policy instruments are regarded as the core concept of policy output but also consider the respective content of the instruments focusing on its setting and calibrations". I shall suggest that policy instruments can be calibrated differently in terms of their explicitness. Explicitness is a dimension or property of policy instruments which refers to their content.

Ideally, the state assesses the desirability of a given regulatory goal—for example, an increase in the availability of donor organs - and then chooses policy instruments that are suitable to achieve this goal (Jordan et al. 2005). However, public policy instruments are more than just means of addressing problems (Bagchus 1998). Public policy instruments also reveal a theorization of the relationship between the government and the governed, and set out the values and interests protected by the state (Lascoumes and Le Galès 2007). Specifically, the use of coercion (at the formal and substantive level) reflects the intensity with which governments attempt to influence target group behaviour-for instance, the consent to donate organs (Schaffrin et al. 2015). Moreover, regulatory density refers to the extent and amount of regulations. The double-edged nature of policy instrumentsaddressing problems and exerting power-is, however, only partly mirrored in the extant taxonomies.

Existing research emphasizes the density, formal intensity and substantive intensity of policy instruments (Adam et al. 2015; Engeli et al. 2013; Studlar and Burns 2015). Essentially, formal and substantive intensities describe the power relationship between the government and the target population (Bauer and Knill 2014; Hood 2007; Howlett and Cashore 2009; Sager 2009; Schaffrin et al. 2015; Vedung 1998). These existing taxonomies focus on regulatory content either as the governments' resources at hand, or as the relationship between public authorities and private actors (Schaffrin et al. 2015). However, none of these categories captures the notion that each of these policy instruments can be neutral (objective) or involve a judgement of desirable behaviour (Vedung 1998: 33).

Let me illustrate this. While both Switzerland and Spain had fully non-coercive awareness-raising campaigns for organ donation in 2010, the sermons differed substantially in the message they communicated. Spain issued the slogan "Donate your organs, donate life". This slogan promoted organ donation very explicitly, yet non-coercively as the desired behaviour. In contrast, the Swiss campaign issued slogans like "Organ donation yes or no", "I know what I want", "I decide myself" and "Does somebody else know what you want?" The Swiss government emphasized the procedural aspect of taking a decision 
regarding organ donation, but without involving any statement about the desired direction of this decision. Against this background, this paper argues that, while highly relevant, neither the notion of "instrument calibrations" nor the dimensions of density or intensity capture the fact that policy instruments differ in the explicitness with which they define a desired direction of behavioural change relative to a given technical policy goal.

The study proposes that existing taxonomies of the substantial intensity of policy instruments be extended to include the dimension of explicitness. It puts forward two main arguments: first, the explicitness dimension captures whether and how policy instruments define an underlying policy goal. On the one hand, policy instruments may or may not indicate a direction of behavioural change (Engeli and Varone 2011). On the other hand, this behavioural change may or may not be attributed positive or negative valence (Kahneman and Tversky 2000; Levin et al. 1998). Not only do information measures or "nudges" display differing degrees of explicitness, but so do more coercive measures (John 2016; Nelson et al. 1997). By decoupling the degree of explicitness from the kind of instrument, this study provides a tool to understand the effects of the intensity of policy instruments, transcending existing notions of "command and control" or "nudging". Second, indicating a direction of desired behavioural change affects how target groups respond to policy instruments (Cialdini 2003; Johnson et al. 2005; Shafir 2013; Thaler and Sunstein 2008; Weaver 2014). A qualitative comparison of organ donation policies in the two cases of Switzerland and Spain illustrates these claims (Manatschal and Thomann 2011). The explicitness dimension provides additional insights that the degrees of density and restrictiveness of the instruments cannot offer.

The next section first reviews existing perspectives on policy design. I discuss how the new dimension of explicitness can complement these perspectives, how it can be measured, and how it might be linked with policy outcomes. The remainder of the article presents the research design and results, discusses the role of context, values and culture, and exemplifies explicitness in two other policy sectors.

\section{Explicitness and the intensity of policy content}

Policy goals are generally recognized as an essential component of policy designs (e.g. Howlett and Cashore 2009). However, the literature features a variety of understandings and measurements of the concept of policy output (Schaffrin et al. 2015). The first, a holistic understanding, stresses that policy output includes both "ends" and "means" at different levels of abstraction (Howlett and Cashore 2009; Howlett 2009). Here, "policy output is composed of three levels of abstraction: the goals of policies, the instruments used to achieve these goals, and the settings in which the policies are applied" (Schaffrin et al. 2015: 258). Policy settings lay out goals through specific requirements. In accordance with these settings, means are calibrated in order to achieve policy goals (Howlett 2009). Different "calibrations" of policy designs provide criteria to classify arrangements of policy tools in view of how means are specified in order to achieve policy goals (Howlett 2009). ${ }^{1}$ While useful for thinking about the choices made by policymakers, this approach does not

\footnotetext{
${ }^{1}$ In addition to calibrated restrictiveness, directness refers to the degree of state involvement in output delivery; automaticity to the degree to which new implementation structures are created; and visibility to budgeting and policy review activities.
} 
comparatively conceptualize different extents to which settings are specified, instruments are calibrated, and goals are defined in the first place.

According to the second, a comparative approach, we can distinguish the density and intensity of policy instruments across time, sectors and countries. Regulatory density tells us about the formal extent and breadth to which governmental activities address a certain policy area (Bauer and Knill 2014). This dimension captures the amount of government activity in terms of the degree of regulatory penetration, complexity and internal differentiation (Knill et al. 2012). Turning to the content (intensity) of government activity, substantial intensity denotes the restrictiveness of policy output in terms of the level (instrument settings) and scope (personal/substantive/temporal) of state intervention. Restrictiveness refers to the substantial freedom left to policy addressees, or the generosity of the services or resources provided (Bauer and Knill 2014: 33; Knill et al. 2012: 430; also discussed as government intervention, authority, stringency, permissiveness or coerciveness by Hood 2007; Howlett and Rayner 2007; Sager 2009; Schneider and Ingram 1990; Vedung 1998). ${ }^{2}$ Finally, formal intensity refers to factors that affect the probability to effectively achieve regulatory requirements, and define the consequentiality of non-compliant behaviour (enforcement, administrative and procedural capacities) (Adam et al. 2015; Knill et al. 2012).

In accordance with this second approach and other than Howlett and Cashore (2009), I separate policy goals from formal and substantial means and label the latter policy instruments (see Schaffrin et al. 2015). ${ }^{3}$ Schaffrin et al. (2015) identify five types of policy instruments in the current literature, which they differentiate along the restrictiveness dimension using Vedung's (1998) tripartite classification of sticks, carrots and sermons. To simplify things, I use Vedung's trichotomy. The three categories distinguish analytically relevant ways of exercising coercion for the purpose of illustrating the notion of explicitness, though they do not capture the more fine-grained degrees of restrictiveness (Sager 2009) or differentiations of different policy instruments (Hood 2007).

Sticks (regulations) are authoritative restrictions on actions or directives as how to act. They limit the choices available to the individuals. Sticks manifest themselves as regulatory measures (Schaffrin et al. 2015) or "authority" (Hood 2007; Howlett and Rayner 2007). Carrots are economic or non-monetary policy instruments. They make an action easier or more difficult by providing or depriving material resources. Incentives make actions less expensive (e.g. subsidies), whereas disincentives make them more expensive (e.g. taxes) - yet the addressees are not obligated to take the measures involved. Both market-based approaches and public investment are carrots, called "treasure" by Hood (2007) and Howlett and Rayner (2007). Finally, sermons are voluntary appeals by means of information or exhortation, characterized by the absence of obligation. Sermons are soft instruments according to Schaffrin et al. (2015) or "nodality" according to Hood (2007) and

\footnotetext{
${ }^{2}$ Restrictive instruments limit the activities, freedom or behaviour of the target group. Permissive instruments contain no or only loose restrictions concerning a specific behaviour, or grant the target groups opportunities for action (Euchner et al. 2013).

${ }^{3}$ Instruments serve to achieve goals, but goals exist independently of instruments. Instruments specify a desired direction of behavioural change with various levels of explicitness, but they do not constitute or contain the behavioural change (the goal) itself.
} 


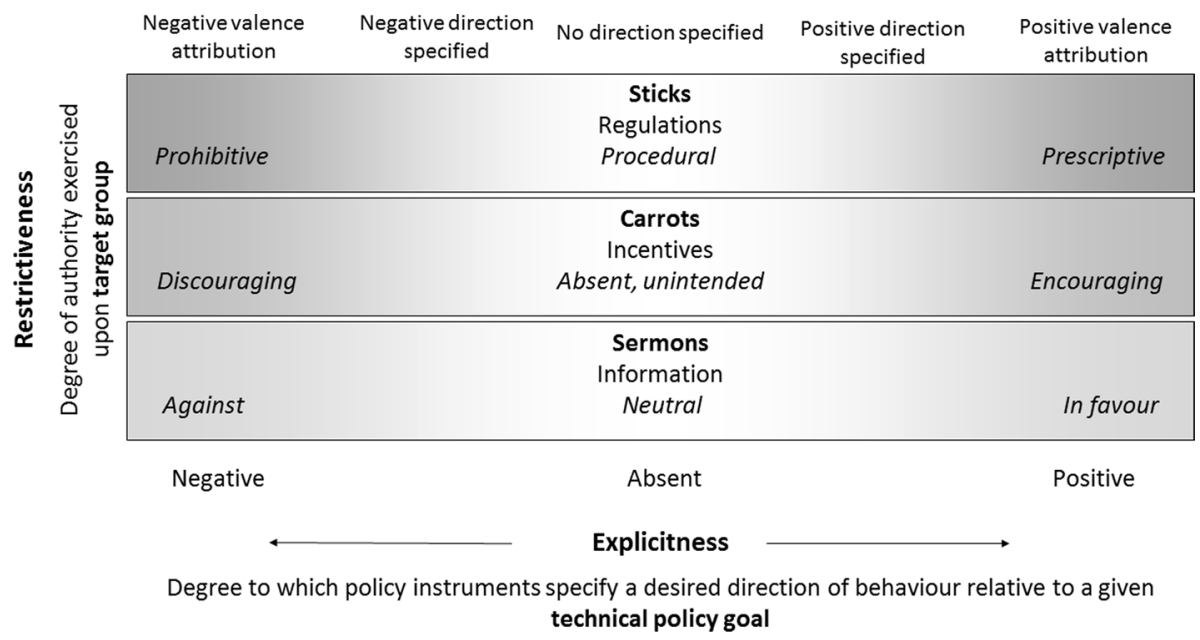

Fig. 1 Explicitness of policy instrument content. Author's illustration, based on Thomann and Manatschal (2016). Italics: examples of respective instruments (not exhaustive)

Howlett and Rayner (2007). ${ }^{4}$ Carrots and sticks can themselves display different degrees of restrictiveness.

The present study argues that policy instruments formulate objectives with varying degrees of insistence (Bagchus 1998; Howlett and Cashore 2009; Howlett 2009; Weaver 2014). As such they include the government's position about the desired technical goal of the policy. The content of policy instruments thus also entails differing degrees of explicitness, meaning the extent to which single instruments specify a desired direction of behaviour relative to a given policy goal. The central analytic question here refers not to the exertion of power, but to whether and how technical policy problems are defined. Jordan et al. (2005) classify different instrument types according to whether or not this is the case. Howlett and Cashore (2009) and Howlett (2009) acknowledge that every output specifies goals through instrument calibrations. However, the authors do not tell the reader the different degrees to which this can be observed. To fill this gap and bridge, to a degree, the two approaches to policy outputs, I argue that any instrument type can in fact specify the policy goal in a more or less explicit manner, see Fig. 1. This figure is a simplified representation of ideal-types; reality is usually more complex.

I will now define the two aspects of explicitness: goal definition and valence attribution, in a positive or negative direction. Based on the example of organ donation policy, I propose a stepwise procedure of comparatively measuring positive and negative explicitness, first for sermons, then for carrots and sticks, and discuss the relationship between explicitness, density, intensity and nudging.

\footnotetext{
${ }^{4}$ Vedung (1998: 38) argues that organizational strategies as a fifth type ("framework policies" according to Schaffrin et al. (2015), sometimes also called "adhesives") are a prerequisite for the application of policy instruments, but not a policy instrument in the narrow sense. If organizational settings cannot meaningfully be classified along the dimensions of permissiveness/coerciveness and explicitness, they are not analysed as policy instruments here.
} 


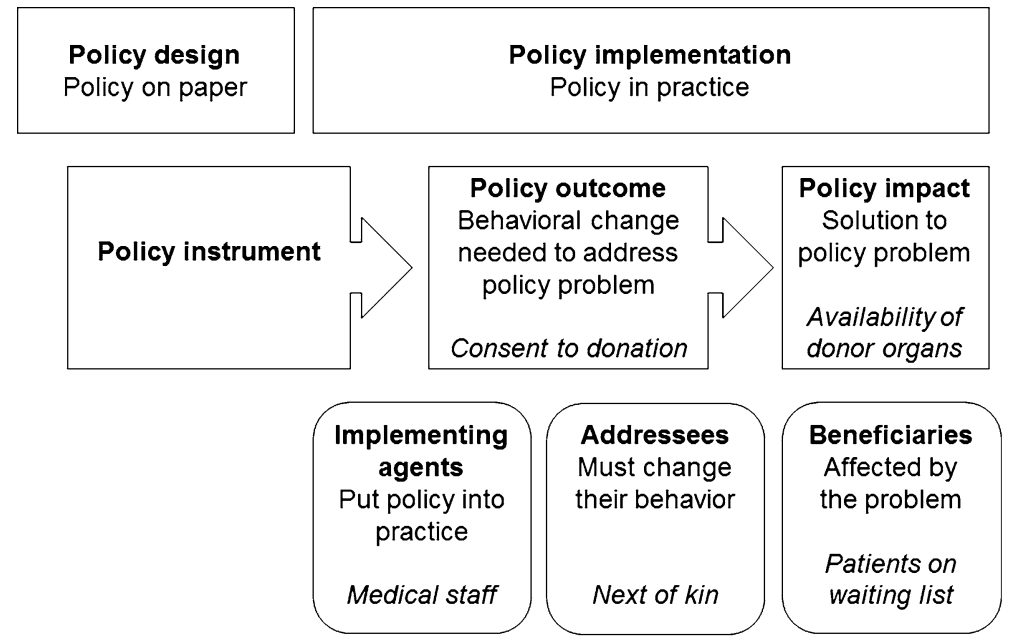

Fig. 2 Policy instrument, outcome and target groups. Based on Knoepfel et al. (2011)

\section{Measuring explicitness}

In its most basic form, explicitness is a dichotomy: either a desired direction of behavioural change is defined, or it is not. Differing degrees of explicitness need to be defined in the specific context of the policy through three consecutive steps: identifying policy outcomes and target groups, goal definition, and valence attribution. Using the example of organ donation policy, I now propose one possible procedure for measurement using these three steps. Neither goal definition nor valence attribution need necessarily be conceptualized in a dichotomous way.

Step 1. Identifying policy outcomes and target groups. This first step starts with identifying the problem(s) that a policy addresses. In order to resolve this problem, policy instruments seek to make certain actors - the addressees of the policy-change their behaviour. This behavioural change, which policy instruments define more or less explicitly, is the policy outcome. The beneficiaries of the policy are the actors who are affected by the problem and hence benefit from the behavioural change, see Fig. 2 (Knoepfel et al. 2011). ${ }^{5}$ The sets of addressees and beneficiaries often overlap, but they differ analytically. For example, to reduce environmental emissions (goal), car producers (addressees) need to comply with standards (instruments) to produce low-emission vehicles (behavioural change). This will then benefit the population (beneficiaries) in terms of improved health.

In the case of organ donation policy, the technical problem is clear: more and more patients in need of transplants are waiting for a donor organ (Flückiger 2010; Matesanz and Dominquez-Gil 2007). The initial pool of potential donors consists of patients with a formal brain death diagnosis or non-heart-beating patients. Once a potential donor has

\footnotetext{
${ }^{5}$ For a specific policy problem, we can usually identify several policy outcomes. Analysing how a given policy output targets different outcomes helps scholars understand the calibration of policy designs. I focus here on explicitness relating to only one policy outcome, while acknowledging that organ donation policy also has other, non-technical goals such as preserving individual freedom.
} 
been identified, the next of kin are asked for their consent or refusal to donate organs. A potential donor turns into an effective donor as soon as at least one solid organ has been retrieved. The number of refusals as a share of total requests for organ donation is the biggest obstacle to higher donor rates. The technical solution lies in lowering these refusal rates (e.g. Dunkel 2011; Roels et al. 2010; Shafer et al. 2006; Simillis 2010; Simpkin et al. 2009).

Figure 2 illustrates that implementing agents who put policy instruments "on paper" into practice may adapt these instruments (Lipsky 1980/2010). Hence, most instruments target more than just one actor group-with differing degrees of density, intensity and explicitness. For example, the Spanish government obliges all hospitals to run a quality control programme (stick; obligatory). However, this programme is intended as an informational measure (sermon; voluntary) for hospital staff to improve organ donation processes. I classify policy instruments according to the degree of authority and explicitness exercised on the final target population (Sager 2009: 540), namely the medical staff and next of kin involved in the family decision-making process.

Step 2. Goal definition. Framing theory tells us that the way in which policy instruments articulate particular problems is a decisive factor in terms of how citizens react to these outputs (Kahneman and Tversky 2000; Nelson et al. 1997). Based on the definition of the problem above, we can identify whether an instrument indicates the envisaged direction of behavioural change (explicit) or not (non-explicit). In the case of organ donation, the question is whether an instrument specifies as the intended behavioural change an increase in the consent rates to organ donation. ${ }^{6}$

To ensure comparability, we need to distinguish positive explicitness (in favour of a given goal) and negative explicitness (contra a given goal). For example, comparative studies of AIDS prevention programmes would reveal that South Africa's campaign under president Thabo Mbeki quite explicitly discouraged effective prevention, whereas Western European countries explicitly emphasized prevention as the intended behaviour. Different instruments might target different, contradictory goals; or some instruments might explicitly target a goal in a positive direction, and others, in a negative direction-resulting in incongruent or contradictory policy designs or instrument mixes (Howlett and Rayner 2007; Howlett 2009). An instrument is more explicit if it aims at positively influencing the donor's decision, as did the Spanish information campaign. Conversely, a non-explicit instrument represents a neutral or absent official position, as did the Swiss information campaign (Dunkel 2011; Flückiger 2010). In such cases, the government avoids taking a position on the morally contested issue of organ donation (Engeli and Varone 2011).

In reality, policy designs are mixes, which can make it conceptually challenging to determine a single policy goal that allows for the operationalization of "directional explicitness". However, it is still possible to assess "mere explicitness" levels (independently of

\footnotetext{
${ }^{6}$ It can be useful to differentiate between the notion of a "goal" as such, and the notion of "intended direction of behavioural change". One could argue that each instrument has some kind of goal, but not always is this goal a direction of behavioural change (in which case it is implicit). Moreover, directional explicitness levels are only directly comparable between instruments with regard to the same goal. To illustrate this, one could argue that both the Swiss and the Spanish cases target values explicitly. The Swiss rules target the value of personal autonomy, and the Spanish rules target the value of saving a life. The Spanish case is more directionally explicit because the ultimate technical goal of the policy in both countries is to save lives by acquiring more organs, not to promote personal autonomy.
} 
directionality) between instruments with different goals, or for a given instrument and its several goals. $^{7}$

Step 3. Valence attribution. An additional question is whether the behavioural change is attributed a valence statement: is there also a positive or negative connotation to the goal? Beyond the mere — and already validating (Mooney 1999) — fact that certain behaviour is explicitly intended, valence attribution refers to the positive or negative meaning that policymakers attach to the policy goal in order to encourage addressees to think and act along particular lines (Chong and Druckman 2007). For example, the message "donate your organs" indicates a direction of behavioural change. "Donate life" additionally attributes a strong positive meaning to this behavioural change. Like goal framing, valence attribution can influence how addressees process information and evaluate behavioural change, for example, whether they perceive this change in terms of gain or loss (Kahneman and Tversky 2000; Levin et al. 1998).

While goal definition establishes the presence or absence of explicitness, valence attribution is especially useful in specifying degrees of explicitness. At the minimum both goal definition and valence attribution allow us to detect non-explicitness (no goal definition and no valence attribution), intermediate explicitness (goal definition but no valence attribution) and high explicitness (goal definition and valence attribution), in either a positive or negative direction relative to a given goal.

\section{Explicitness, restrictiveness, formal intensity and density}

Not only do non-coercive sermons define goals more or less explicitly, but so do all types of policy instruments. Specifying the explicitness of carrots and sticks highlights the conceptual and empirical relationship between the different dimensions of density, formal intensity, restrictiveness and explicitness. In order to establish explicitness as a separate dimension of policy instruments, I illustrate this relationship and show that explicitness can nevertheless vary at comparable levels of density and restrictiveness.

Sticks. Sticks, too, often define goals since they prohibit behaviour or encourage the same behaviour; or they can be non-explicit, for example, procedural. A procedural stick could create the duty to perform certain formal steps and assign implementing actors, while delegating the choice of the objective of these steps and their concrete design to the implementing actors (Engeli and Varone 2011). ${ }^{8}$ One example of a non-explicit stick is informed consent: it requires a choice to be made, but leaves the direction of the choice completely to the hands of the donor's relatives. Conversely, the presumed consent model is a more explicit stick than informed consent. It assumes that everyone is a potential donor unless the relatives opt out. It formulates organ donation as the intended behavioural change, even if it does not impose organ donation (Johnson and Goldstein 2003). The way in which valence attribution manifests itself depends on the specific context of each case. Generally, sticks can attribute positive or negative meaning to

\footnotetext{
${ }_{7}$ I am grateful to a very helpful reviewer for encouraging me to make this point.

8 One reviewer has rightly noted that some procedural regulations can be quite explicit. For example, "safety cultures" can go from the less directionally explicit-"safety is everyone's business"-to the very explicit "one death in the workplace is one too many". The defining feature of an implicit instrument (of any type) is not whether it is procedural, but that it neither specifies a desired direction of behavioural change, nor attaches valence to it, with regard to a goal (such as enhancing safety).
} 
a certain behaviour. For example, the size of the fine for fast driving can indicate the importance of traffic accident prevention for a government (Adam et al. 2015).

Carrots. Measuring goal definition is trickier for carrots than for sermons and sticks. Other than the latter, incentives and disincentives inherently indicate some direction of behaviour and would ideally only be fully non-explicit when absent (Schneider and Ingram 1990). Arguably, for carrots, the intentionality of goal definition requires attention (Knoepfel et al. 2011; Vedung 1998). For example, relatives of potential organ donors face non-material costs of separation if the body has to be transported to a retrieval hospital. When designed, this organizational measure was not intended as a disincentive to giving consent, but it clearly needs to be classified as such (Simillis 2010). Still, the instrument itself does not explicitly formulate any goal. Hence, non-explicit carrots neither purposefully encourage nor purposefully discourage a given behaviour. In the field of organ donation, we can think of explicit (positive) incentives as carrots encouraging consent: for example, if hospital donor coordinators receive financial rewards for recruiting donors. Explicit negative incentives would be carrots that purposefully discourage giving consent to donate organs. Carrots often assign a concrete value-material or other-to certain outcomes, implying greater costs or rewards for the addressees.

While intertwined, the dimensions of density, substantive and formal intensity, and explicitness refer to different aspects of the quantity and quality of state action: just as body size and body weight are two distinct but interrelated indicators of someone's physical appearance. This is not a problem of the explicitness concept; it applies equally to the relationship between density and restrictiveness. For example, more restrictive measures can, but do not have to coincide with a higher density of prohibitions; just as heavier people are often, but do not have to be taller than lighter people (Adam et al. 2015). Equally, however, sometimes regulators add density to regulations to create exemptions, leading to less restrictive regulations (Thomann and Zhelyazkova 2017). It would be wrong to say that density and restrictiveness are independent-just as body size and body weight also correlate-but they are clearly distinct. Similarly, explicitness can sometimes coincide with different degrees of density, formal intensity and the ambiguity of goals and tasks, amongst others. Notwithstanding this interrelationship, explicitness is a separate analytic dimension of policy instruments, measured via two questions: first, does an instrument indicate a desired direction of behavioural change? Second, is positive or negative valence attached to this goal? Neither regulatory density (quantity of regulation), regulatory restrictiveness (leeway left to regulatees) nor formal intensity (efforts to achieve compliance) addresses these questions.

Still, these aspects can sometimes inform explicitness. For example, the amount of educational measures can be one indicator that a government attributes high valence to behavioural change (e.g. awareness about organ donation). Yet, two countries can have a similar density of educational campaigns which still differ in the explicitness with which they encourage organ donation. Clearly, the density of output is not identical to the explicitness of an instrument. Similarly, if a government prescribes a certain behaviour, then it formulates this behaviour as a goal. However, the different models of consenting to organ donation also show that instruments can have the exact same level of restrictiveness and still differ in their explicitness. Hence, restrictiveness does not equal explicitness. Finally, the high cost of non-compliance (e.g. a prison sentence) attaches value to certain behaviours. Despite this, this cost could be equally high for two sticks, one being merely procedural and the other, highly explicit. Obviously, formal intensity is distinct from explicitness. 


\section{Explicitness and nudging}

Given its behavioural dimension, one could conclude that explicitness is simply a nudge. A nudge "is any aspect of the choice architecture that alters people's behaviour in a predictable way without forbidding any options or significantly changing their economic incentives. To count as a mere nudge, the intervention must be easy and cheap to avoid. Nudges are not mandates. Putting fruit at eye level counts as a nudge. Banning junk food does not" (Thaler and Sunstein 2008: 5). Given this broad definition, "the boundaries for qualifying an intervention as a nudge are clearly a little blurred" (Oliver 2013: 694). Prominent examples of nudges include defaults, information nudges and self-control nudges, such as simplification, the use of social norms, increases in ease and convenience, disclosure, warnings, precommitment strategies, reminders, eliciting implementation intention, and information about the consequences of earlier decisions (see John et al. 2011).

Explicitness is an analytic dimension of every policy instrument, regardless of its coerciveness and form. Conversely, nudges are certain non-coercive instruments that work at the psychological level, and whose goal is typically covert (Oliver 2013) rather than explicit. Explicitness is a precise measurable quality of instruments that does not yet refer to their effects. Conversely, the concept of a nudge is much fuzzier and mainly defines itself through its effect on the regulatees. Clearly, then, explicit policy instruments can-but do not necessarily always-have the form or effects of nudges. For example, many argue that an opt-out solution to giving consent to organ donation is a nudge. Yet equally clearly, explicitness (as an analytic feature of every policy instrument) and nudges (as specific, non-binding instruments informed by behavioural considerations) are not the same thing.

In summary, the added value of assessing the explicitness of policy instruments lies in shedding light on an additional aspect of their content: the degree and quality of goal definition. Similar to the notion of nudging, explicitness helps us understand how policy instruments shape the decision environment of target groups.

\section{Explicitness and policy outcomes}

The degree of goal ambiguity of a policy influences its implementation (Baier et al. 1986; Matland 1995). Accordingly, explicitness should help us understand the consequences of policy instruments on target groups. The emerging literature on behavioural public policy supports this assertion (John 2016). Policy instruments structure the decision environment of target groups (Shafir 2013). Governments communicate messages of different intensities through policy instruments (Cialdini 2003). The behavioural assumption is that individuals are more likely to take action in support of policy goals if the goals are promoted by government officials as important (Schneider and Ingram 1990: 519). The way in which messages are formulated matters, as oftentimes "people do not have well-defined preferences for (...) particular questions, (...). Rather, people may construct preferences at the time the question is asked" (Johnson et al. 2005: S17). For instance, many people prefer to stick to the default set out by governments rather than making an active choice (Johnson and Goldstein 2003). The intensity of the message can greatly affect how people perceive and respond to policy instruments by 
changing beliefs about the goal, activating, or altering the priority of existing beliefs (Chong and Druckman 2007; Kahneman and Tversky 2000; Nelson et al. 1997; Weaver 2014).

What can we learn from this literature (see Van der Heijden and Kosters 2015; Oliver 2015)? Even if target groups may not always respond as desired, explicitness can work as one-albeit not the only-aspect of the choice architecture that makes certain behaviours more or less likely (Thaler and Sunstein 2008). The degree of explicitness of policy instruments lends more or less credibility to state action. For example, relatives may perceive the organ donor request as more authentic if they know that the government's position is that it saves lives (Thomann and Manatschal 2016). Conversely, by not explicitly stating the desired direction of behavioural change, non-explicit policy instruments are not designed to achieve technical policy goals:

Expectation: Non-explicit policy instruments tend to be less effective than explicit instruments in resolving the technical problem.

\section{Research design}

A comparison of the Swiss and Spanish organ donation policy illustrates these arguments. The Spanish organ donation system is an example of best practice with the highest deceased donor rates worldwide. Conversely, Switzerland "lags behind": Table 1 illustrates that Swiss refusal rates exceeded Spanish rates by 2.5 times in 2009. Furthermore, refusal rates differ strikingly between the German-speaking and the French- and Italian-speaking (=Latin) regions, and are clearly higher in larger than in smaller hospitals. ${ }^{9}$ Neither do refusal rates differ significantly from region to region nor are refusal rates notably higher in larger hospitals in Spain. Hence, different types of hospitals (small vs. large) constitute "nested" cases within two national contexts (Switzerland and Spain) and three regional contexts (German-speaking and Latin regions of Switzerland, and Spanish regions). ${ }^{10}$ This design enables me to assess the robustness of my expectation across different value contexts (Levi-Faur 2006).

Prior to 2007, organ donation policy in Switzerland was unregulated at the national level. In contrast, Spain issued a national Transplantation Act as early as 1979 and founded the Organización Nacional de Trasplantes (ONT) in 1989. The Spanish model was exported to various countries all over the globe (Matesanz and Dominquez-Gil 2007; Matesanz 2008; Quigley et al. 2008). In light of fast-growing waiting lists, the Swiss Transplant Act "copied" the basic elements of the Spanish model—hence all the sermons, carrots and sticks are present in both countries. The countries are also comparable in organizational terms. Both organ donation sectors are based on a three-tiered coordination system (national, regional, hospital). Each hospital with an intensive care unit (ICU) has at least one person responsible for donation and transplantation activities. In addition, religious values are translated with similar intensity in both countries (Engeli et al. 2013; Engeli and Varone 2012). This similarity, together with identical levels of restrictiveness, facilitates identifying different levels of explicitness.

\footnotetext{
${ }^{9}$ Large hospitals have a neurosurgery department, whereas small hospitals generally do not.

${ }^{10}$ Since the Spanish Model of organ donation was established before the decentralization of Spain's health care system, it is uniformly implemented in all regions (Manatschal and Thomann 2011: 46).
} 


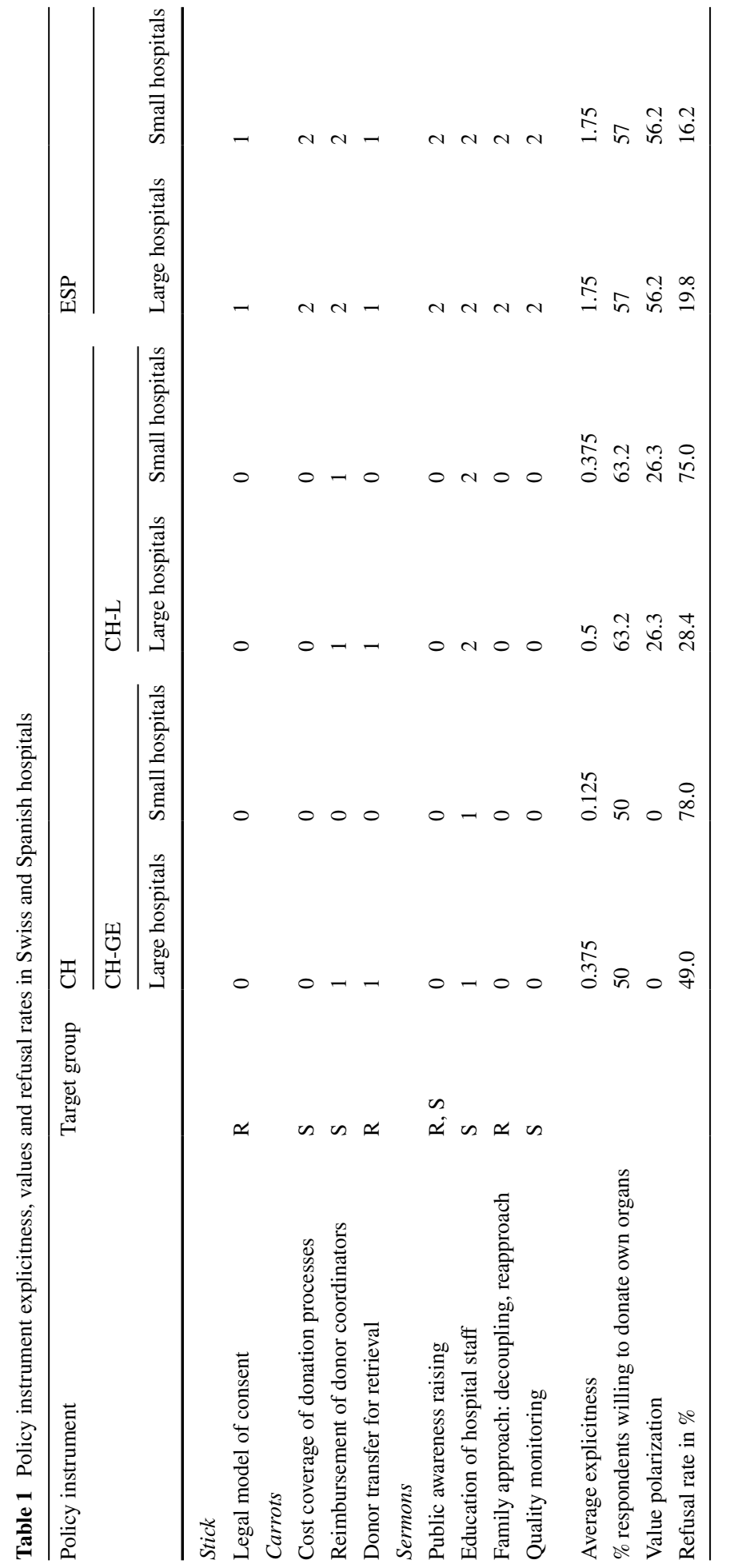

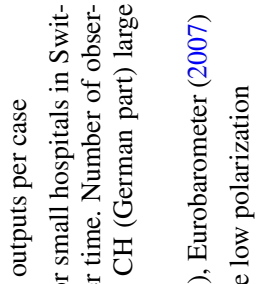

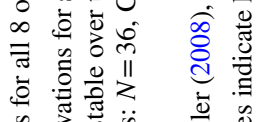



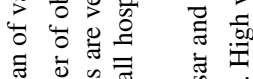

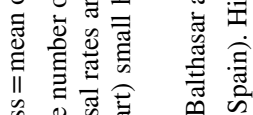

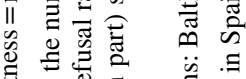

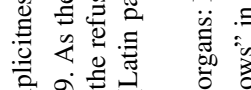

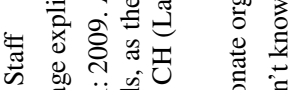

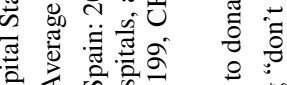

की की

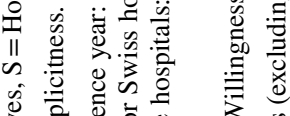

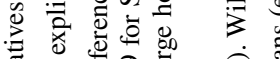

离

II 获

幽

홍

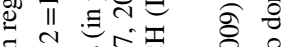





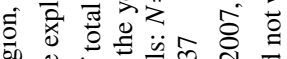



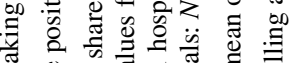

ฮ

की



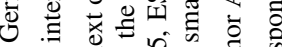

II II

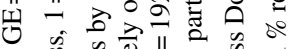


की : II 家 ज为 i

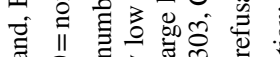

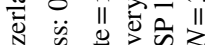

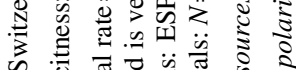

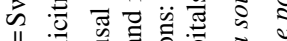




Given the novelty of the posited argument, this paper has an explorative and indepth focus. To illustrate the link between the degree of explicitness of the policy instruments and refusal rates, explanatory typologies are used to complement the qualitative case studies to connect different combinations of values of explanatory variables with particular outcomes (Elman 2005). These patterns are then substantiated through the case studies as well as through previous empirical evidence from other studies.

Data sources and measurement. Information regarding policy instruments and their effects were collected in 2010 for the Federal Office of Public Health (FOPH) through a qualitative content analysis of primary and secondary literature, and semi-structured interviews with a total of 28 experts and practitioners in both countries (Manatschal and Thomann 2011; see Table 2). Data on refusal rates stem from the national quality monitoring programmes. The Spanish sample comprises all hospitals in 2009 (71 big, 68 small hospitals), whereas data are only available for $50 \%$ of the Swiss hospitals. The participant hospitals are considered representative (Manatschal and Thomann 2011: 33, 64). Finally, the survey question "would you be willing to donate one of your organs to an organ donation service immediately after your death?" serves as a proxy for values on organ donation. In Spain, a special Eurobarometer was conducted in $2006(N=749)$ (Eurobarometer 2007). In Switzerland, a representative health survey was carried out in $2007(N=13304)$ (Balthasar and Müller 2008). Value polarization denotes the difference between the share of positive answers and the share of negative answers of all respondents expressing an opinion (excluding “don't knows").

\section{Results}

Table 1, which presents the substantial content of the two countries' regulatory regimes, offers two important insights.

First, both countries have adopted policy instruments with similar degrees of coerciveness, which hence cannot account for the striking differences in refusal rates. Second, Spanish hospitals have the most explicit instrument logic, followed by the Swiss Latin-speaking ones, and finally the German-speaking hospitals. In line with Howlett and Cashore's (2009) notion of design logics, this pattern begins with the objectives defined by the national transplant acts: the Spanish law explicitly aims to encourage voluntary, altruistic and non-remunerative organ donation to ensure that every citizen in need of a donor organ has optimal chances of receiving one. Conversely, the Swiss law simply seeks to regulate the processes of organ donation.

As Fig. 3 illustrates, more explicit policy instruments tend to come with lower refusal rates. The case study evidence and other empirical studies highlight the mechanisms underlying this link, while also suggesting that explicitness is not the only factor that matters. ${ }^{11}$ Large hospitals in Latin-speaking Switzerland deviate from this picture, as discussed below.

\footnotetext{
${ }^{11}$ Generally, the comparison between large Swiss German-speaking hospitals and small Swiss Latinspeaking hospitals suggests that in addition to explicitness, hospital size, reflecting hospital infrastructure and more conservative values in rural areas, matters for refusal rates.
} 




Fig. 3 Explicitness and refusal rates. Sources: Manatschal and Thomann (2011); ONT (2009); Swiss Donor Action (mean of 2007, 2008, 2009)

\section{Stick}

The legal model of consent is a stick because it obliges the relatives of potential organ donors to take a decision (Abadie and Gay 2006). Under presumed consent (opt-out), which applies in Spain, everyone is explicitly considered to be a potential donor. Relatives must take an active step to express their opposition to a donation. By contrast, Switzerland's informed consent (opt-in) system makes no such explicit assumptions: relatives must express their agreement to donating. Neither solution attaches valence to consent.

Legal defaults are often considered recommendations made by governments and are considered so powerful that they can "save lives" (Johnson and Goldstein 2003; Johnson et al. 2005). Yet the evidence is most ambiguous regarding this factor. Several studies report that presumed consent is positively correlated with higher donation rates (Abadie and Gay 2006; Johnson and Goldstein 2003; Mossialos et al. 2008). Others, however, find no clearly isolable influence of presumed consent on refusal rates (Bilgel 2012; Matesanz and Dominquez-Gil 2007; Simillis 2010). In their systematic review of the existing evidence, Rithalia et al. (2009: 1) conclude that "presumed consent alone is unlikely to explain the variation in organ donation rates between countries". Instead, a policy regime that includes instruments that explicitly support organ donation at all levels is needed. The legal model of consent is only one part of this puzzle.

The interviewees had the same core message. The Spanish interviewees pointed out that although Spain has had an opt-out solution since 1979, refusal rates only decreased after the ONT and the corresponding regime of explicit policy instruments 
was implemented in 1990. In practice, relatives are always asked for their consent in both countries (Quigley et al. 2008: 223). This "reduces the effectiveness of prompted choice to increase the number of available organs" (Oliver 2015: 706). The legal model mainly influences the concrete wording of the organ donation request, which then interacts with population awareness (Mossialos et al. 2008) and the attitudes of critical care staff (Roels et al. 2010) to influence the calibration of the family approach at the hospital level (Manatschal and Thomann 2011). Overall, the practice of the family request in hospitals, to which I turn below, is vastly more important than the recommendation that the default entails.

\section{Carrots}

\section{Cost coverage and reimbursement of coordinators}

Donation processes are specifically funded in Spain, which recognizes the economic value of donor recruitment. This is not the case in Switzerland. The Spanish health budget covers all procedures preceding the actual organ retrieval within a system of advance payment, irrespective of the eventual success of the procedures. Conversely, until 2012, cost coverage in Switzerland did not include any procedure preceding organ retrieval, such as the donor request, nor did it include cost coverage for situations in which an organ was retrieved, but not transplanted. Turning to reimbursement, Spanish intensive care unit (ICU) staff and coordinators explicitly receive compensation for their work in donation processes (Matesanz 2008: 23) (both goal definition and valence attribution). Conversely, Swiss organ donation coordinators in hospitals (so-called donor key persons) are paid part-time for their coordination activities in the Programme Latin de Don d'Organes (PLDO) and in large hospitals in German-speaking Switzerland (goal definition, considerably less valence attribution than in Spain), but not in small German-speaking hospitals (no goal definition, no valence attribution).

Economic resources create incentives for staff to put efforts and expertise into recruiting donors. The motivation of the coordinators rests partly on the appropriate payment for coordination activities. The Spanish incentive structure works not least due to the surgeons' comparatively low basic salaries (Matesanz and Dominquez-Gil 2007: 184). Conversely, the lack of explicit financial compensation in small German-speaking hospitals is often perceived as a devaluation of the donor coordination function, hence working as an (unintended) disincentive for the commitment of the coordinators.

\section{Donor transfer}

Transfers to larger hospitals for organ retrieval impose the non-material cost of physical separation from the beloved deceased on the already traumatized relatives. In Spain, mobile teams of surgeons travel to small hospitals for organ retrieval-a measure explicitly targeted at avoiding refusals due to donor transfer (Matesanz 2008). Conversely, in small Swiss hospitals, about one-third of the donors were transferred to a larger hospital for retrieval in 2009 (Swisstransplant 2009). This carrot does not entail an explicit 
valence attribution. Explicitly avoiding donor transfer mediates the concerns of relatives about what will happen with the deceased's body, and this demonstrably helps avoid refusals (Simillis 2010). In contrast, the psychological stress of not being able to "say goodbye" is reportedly an important reason why relatives refuse organ donation in small Swiss hospitals.

\section{Sermons}

\section{Public awareness raising}

The ONT promotes donation explicitly and coherently via close media relations, information campaigns and frequent education programmes at schools and universities, thus reaching a broad public. Not only is the goal clearly stated, it is positively framed as a way to save lives. Conversely, the Swiss law obliges the FOPH to remain strictly neutral in its public information campaign (information website, placards, advertisements and non-compulsory teaching materials). Swisstransplant takes a more pro-donation stance, resulting in ambiguous messages (BAG 2008; Manatschal and Thomann 2011; Matesanz and Dominquez-Gil 2007; Schulz et al. 2006). Explicit awareness-raising campaigns like the Spanish ones influence the population's knowledge of and attitude towards organ donation. This reduces possible fears associated with organ donation, which can result in a greater desire to donate (Mossialos et al. 2008; Schulz et al. 2006).

\section{Education of hospital staff}

In Spain, regional authorities and hospital coordinators systematically and comprehensively educate and make hospital staff aware of organ donation (Matesanz 2008). This training includes specific techniques used to communicate the positive aspects of organ donation. In Switzerland, the FOPH only selectively supports courses for donor key persons focused on communication with relatives. The PLDO network coordinators occasionally offer additional courses. Overall, Switzerland does educate hospital staff, but this education takes a more comprehensive, intensive and positively framed form in the PLDO (BAG 2008; Swisstransplant 2008: 7). There is ample evidence that comprehensive educational programmes for staff indirectly help reduce refusal rates: differences in staff awareness clearly affect the decisions of relatives to donate organs (Roels et al. 2010; Siminoff et al. 2001; Simpkin et al. 2009 Indeed, in German-speaking hospitals, the organ donation topic was a taboo and was marginalized. Conversely, the network coordinators in Spain and the PLDO worked hard to maintain a commitment and motivation to integrate donation activities in hospitals.

\section{Family approach (performance of donor request)}

In Spain, hospital coordinators are involved in the entire family decision-making process and take comprehensive care of the relatives. The family approach in Spain explicitly integrates several techniques aimed at minimizing refusal rates. The donor request is made by a different person than the notification of death and is made some time after (personal and 
temporal decoupling). If the relatives' initial reaction is negative, the request is repeated several times (reapproach). Hence, the Spanish approach is geared towards maximizing consent and communicating that consent is something desirable. In Switzerland, the family approach is more neutral. The donor key persons are not explicitly responsible for making the donor request (BAG 2008). Brain death diagnoses and requests are usually neither temporally nor personally decoupled. The practice of reapproach is negatively perceived and never applied (Manatschal and Thomann 2011: 53, 70, 112). This approach does not have consent as its explicit goal. The techniques of temporal and personal decoupling and reapproach clearly decrease the likelihood of refusal and may lead relatives to reconsider their decision if they were initially undecided (Matesanz 2008; Siminoff et al. 2001; Simpkin et al. 2009).

Programmes for quality control Finally, national programmes for quality control aim at systematically reporting and optimizing organ donation processes. Spain has a comprehensive, systematic evaluation programme of the reasons for family refusals, the results of which are published to facilitate systematic improvement. The comparison of hospitals has resulted in the spread of good practices and a positive validation of "high performers". In contrast, Switzerland runs a voluntary and incomplete programme, which until 2009 neither evaluated the causes of family refusals nor published its results. Diminishing refusal rates is not its goal. The targeted quality control programme motivated the Spanish interviewees to improve their performance, which was not the case in Switzerland.

These results support the assertion that explicitness is influential in structuring the decision-making environment for target groups. But what explains the comparatively lower refusal rates in large hospitals in Latin-speaking Switzerland despite rather low overall levels of explicitness? Apart from the family approach, the three proximate instruments that directly impact on the everyday lives of staff and relatives in hospitals are all explicitly in favour of consent in the PLDO. Interviewees highlight that the explicit practice of reapproach is perceived as extremely intrusive and would work dissuasively in the Swiss cultural context. Thanks to their education, the medical staff in these hospitals is better skilled to sensitively communicate the donor request than in the other Swiss hospitals. This case illustrates that in order to be effective, instruments must be appropriate, and this may vary in different contexts (Thomann and Manatschal 2016). This insight raises a number of questions.

\section{Explicitness, values and context}

It is difficult to think of explicitness without considering the underlying cultural context, that is, the values, norms, rules, strategies shared, used and applied in the everyday life of people living within a society (Dunkel 2011: 68). Values are relatively stable individual preferences regarding desirable end states or motivations. Values guide people's selection or evaluation of behaviour and events and express themselves in attitudes (Bilsky and Schwartz 1994: 164; Maio and Haddock 2009: 38). As Table 1 shows, German-speaking Swiss people have the least organ donation-friendly culture compared to Spain and Latinspeaking Switzerland (Dunkel 2011; Schulz et al. 2006). ${ }^{12}$ These cultural differences are

\footnotetext{
12 The religious notion that bodily integrity should be maintained is of low importance in both countries (Newton 2011).
} 
rooted in the varying degrees to which death is a taboo topic, the importance of altruism, the "moralization" versus normality of organ donation, the role of community and family, and trust in the medical profession (Dunkel 2011; Euchner et al. 2013; Manatschal and Thomann 2011; Newton 2011; Schulz et al. 2006). This context affects the adoption and effectiveness of policies in general (Studlar and Burns 2015, 288) and the motivations, knowledge, and barriers associated with organ donation policy, in particular (Mossialos et al. 2008; Simillis 2010).

However, given the striking differences between different types of hospitals in the same cultural context, refusal rates are obviously not simply a function of values and the resulting attitudes. Table 1 also shows that the basic intention to donate is surprisingly weakly related to actual donor decisions (see also Radecki and Jaccard 1999). Despite similar levels of willingness to donate (57\% of the Spanish, and $53 \%$ of the Swiss population in 2007), actual donor rates vary dramatically and are considerably lower than the levels of willingness to donate. Policy instruments influence what happens between the abstract intention to donate, and the actual consent to donate.

It is beyond the scope of this paper to provide a comprehensive answer as to why policy instruments display differing degrees of explicitness (see Engeli et al. 2013; Euchner et al. 2013). In policies that concern fundamental questions such as when life begins or ends, each intervention represents a "legal sanction of right and wrong, the validation of a particular set of basic values" (Mooney 1999: 675). Yet, Table 1 confirms that these values themselves do not directly translate into different degrees of explicitness of policy instruments. Conversely, Table 1 lends some support to the assertion that if values within a constituency are highly polarized, then governments may prefer to avoid an explicit position (Engeli and Varone 2011). ${ }^{13}$ However, Knill et al. (2015) also show that many other countries have highly explicit policy regimes despite high levels of issue contestation.

Undoubtedly, public policies simultaneously reflect prior public attitudes, values and morals, and can change the latter (Coleman 1990; Mossialos et al. 2008: 5-6). Accordingly, "to alter the policy instrumentation not only calls for an expansion of the toolbox, but also for a cultural change" (Bagchus 1998: 64). Equally, as the case of large hospitals in Latin-speaking Switzerland illustrates, some policy instruments work better than others in certain contextual situations. Hence, policy makers need to identify the right instrument in the appropriate context (John 2016). However, the case studies presented here and ample scientific research documents the mechanisms underlying the way in which levels of explicitness influence refusal rates. Neither of these are simply a function of values.

\section{Discussion}

The existing literature recognizes the central role of policy goals for policy instruments and emphasizes how policy instruments structure the relationship between the government and the governed, but it neglects how instruments structure the decision environment of target groups. The explicitness dimension captures the messages sent out to citizens by defining the direction of the desired behavioural change (Chong and Druckman 2007; John 2016; Kahneman and Tversky 2000; Levin et al. 1998; Nelson et al. 1997).

\footnotetext{
13 Indeed, we can think of non-explicitness as ambiguity about the goal of an instrument (Matland 1995). Ambiguous policies are often chosen to limit conflict because "policy ambiguity allows different groups and individuals to support the same policy for different reasons and with different expectations" (Baier et al. 1986: 206).
} 
As another aspect of substantial intensity, the explicitness dimension complements the traditional focus on instrument density, formal intensity and restrictiveness when thinking about the settings and calibration of policy output (Bauer and Knill 2014; Knill et al. 2012, 2015; Engeli et al. 2013; Hood 2007; Howlett 2009; Sager 2009; Schaffrin et al. 2015; Vedung 1998).

The findings suggest that the explicitness of governmental messages does affect how target groups respond to policy instruments. Individuals appear more likely to support policy goals that the state and public actors explicitly promote as important and desirable. Differing degrees of explicitness lend credibility and meaning to the context in which target group behavioural change takes place (Cialdini 2003; Johnson et al. 2005; Schneider and Ingram 1990; Shafir 2013; Thaler and Sunstein 2008; Thomann and Manatschal 2016; Weaver 2014). By conceptualizing regulatory regimes as an ensemble of instruments that operationalize overarching policy objectives (Howlett and Cashore 2009), the findings of this study relativize the "power of defaults" (Johnson and Goldstein 2003; Johnson et al. 2005). Defaults are only single instruments the effects of which depend on the overall policy regime and on how the default is put into practice (Van der Heijden and Kosters 2015; Rithalia et al. 2009). Instruments designed to manipulate target group behaviour might not work as intended if not properly calibrated to the context (Oliver 2015).

This explorative study aimed to qualitatively assess how the explicitness concept facilitates a deeper understanding of the cases under study (Elman 2005; Levi-Faur 2006). It considered the interplay between three key variables of interest but did not provide a comprehensive, statistically generalizable explanation that controlled for developments over time. Future research should analyse the prevalence, reasons and consequences of explicitness in other contexts and over time so that a causal inference can be drawn. This is important because explicitness levels are not a panacea for achieving policy outcomes. Rather, they are closely intertwined with the prevailing culture of the population (Coleman 1990). Studying explicitness levels helps illuminate the inherent "trade-off between appropriateness and fit of policy instruments" (Bagchus 1998).

\section{Conclusion}

Beyond the context of organ donation policy, the explicitness concept can also inform other areas such as air pollution regulation. One technical solution to air pollution is that car drivers use low-emission vehicles. To achieve this, governments may simply provide information about existing carbon dioxide emissions to car buyers (a non-explicit sermon), or it could advise them to buy cars with low emissions (an intermediately explicit sermon). This message would be highly explicit, for example, if the negative consequences of pollution were also highlighted (positive valence of low emissions). Financial incentives for buying low-emission cars constitute a positive, highly explicit carrot (goal definition and high economic value attached); price caps for low-emission cars an intermediately explicit carrot (behavioural change is defined but less valence attached), whereas the absence of price regulation is a non-explicit carrot (no goal definition, no valence attribution; a de facto disincentive for buyers). Finally, as the case of Volkswagen illustrates, the obligation for car producers to test car emissions is a non-explicit stick if the regulator attributes low valence to compliance with emission thresholds.

Food safety regulation is another example for differing levels of explicitness (Thomann 2018). For instance, both Germany and the UK have developed information 
campaigns and voluntary standards for producers to reduce antibiotic resistance in livestock production. These sermons explicitly highlight the importance of this objective for human health (positive valence attribution). France, Switzerland and Austria also envisage the possibility of voluntary written agreements between livestock holders and veterinarians, which would tie simplified access to veterinary drugs with monitoring and education requirements (carrot). Yet, only the Austrian agreements explicitly envisage the reduced use of antibiotics, and none of them attach value to such a reduction. Finally, some countries allow the on-farm manufacture of medicated feed (OFM), again tied to several conditions (sticks). Although they vary in their degree of restrictiveness, these conditions explicitly aim at avoiding antibiotic residue during OFM (Thomann 2018). What this discussion shows is that the explicitness of instruments may vary at similar levels of restrictiveness, density or formal intensity, while instruments of differing restrictiveness may actually be similarly explicit. The question future research should tackle is how this affects regulatory outcomes.

Regardless of the policy analysed, the explicitness dimension contributes to capturing the calibration and underlying "instrument logics" of policy mixes (Howlett and Cashore 2009; Lascoumes and Le Galès 2007). Accounting for explicitness also helps conceptualize policy designs that target differing, incoherent goals or goals that are incongruent, that is, when instruments do not match the goals (Howlett 2009; Howlett and Rayner 2007). Moving beyond both "command and control" and nudging approaches, this article has emphasized that explicitness is not specific to one type of instrument; accordingly, information instruments, but also binding regulations can be more or less explicit. The explicitness of policy instruments has proven more insightful than the coerciveness of policy instruments in terms of understanding the empirical cases discussed here. By not accounting for degrees of explicitness, researchers might actually overlook an important part of the picture behind the emergence, change and effects of policy instruments (Adam et al. 2015; Bauer and Knill 2014; Knill et al. 2012; Schaffrin et al. 2015). Including this perspective can, therefore, contribute to a better understanding of how governments define and resolve problems in their continuous attempt to balance responsiveness to target populations with social change.

Acknowledgements I want to wholeheartedly thank Anita Manatschal for first issuing the idea of explicitness. I am also very grateful to Christian Adam, Emma Budde, Anat Gofen, Sreeja Nair, Moshe Maor, Lyn Pleger, Fritz Sager, Ilana Shpaizman, Jale Tosun, Kent Weaver, Reimut Zollnhöfer and the anonymous referees for their immensely helpful feedback on earlier versions of this paper. The usual disclaimer applies.

Open Access This article is distributed under the terms of the Creative Commons Attribution 4.0 International License (http://creativecommons.org/licenses/by/4.0/), which permits unrestricted use, distribution, and reproduction in any medium, provided you give appropriate credit to the original author(s) and the source, provide a link to the Creative Commons license, and indicate if changes were made.

\section{Appendix}

See Table 2 . 







\section{References}

Abadie, A., \& Gay, S. (2006). Impact of presumed consent legislation-A cross country study. Journal of Health Economics, 25(4), 599-620.

Adam, C., Hurka, S., \& Knill, C. (2015). Four styles of regulation and their implications for comparative policy analysis. Journal of Comparative Policy Analysis: Research and Practice. https://doi. org/10.1080/13876988.2015.1082262.

Alemanno, A., \& Sibony, A.-L. (2015). Nudge and the law: A European perspective. London: Bloomsbury Publishing.

Ayres, I., \& Braithwaite, J. (1992). Responsive regulation: Transcending the deregulation debate. Oxford: Oxford University Press.

Bagchus, R. (1998). The trade-off between appropriateness and fit of policy instruments. In B. G. Peters \& F. K. M. Van Nispen (Eds.), Public policy instruments. Evaluating the tools of public administration (pp. 46-66). Cheltenham/Northampton: Edward Elgar.

Baier, V., Eaton, J. G. M., \& Saetren, H. (1986). Implementation and ambiguity. Scandinavian Journal of Management Studies, 2(3), 197-212.

Balthasar, A., \& Müller, F. (2008). Auswertungen ausgewählter Daten der Schweizerischen Gesundheitsbefragung 2007 zum Bereich Transplantation. Bern: Bundesamt für Gesundheit.

Bauer, M. W., \& Knill, C. (2014). A conceptual framework for the comparative analysis of policy change: Measurement, explanation and strategies of policy dismantling. Journal of Comparative Policy Analysis: Research and Practice, 16(1), 28-44.

Bilgel, F. (2012). The impact of presumed consent laws and institutions on deceased organ donation. The European Journal of Health Economics, 13(1), 29-38.

Bilsky, W., \& Schwartz, S. H. (1994). Values and personality. European Journal of Personality, 8(3), $163-181$.

Bundesamt für Gesundheit (BAG). (2008). Faktenblatt Transplantationskoordination und lokale Koordination. Bern: Bundesamt für Gesundheit.

Chong, D., \& Druckman, J. N. (2007). Framing theory. Annual Review of Political Science, 10, $103-126$.

Cialdini, R. B. (2003). Crafting normative messages to protect the environment. Current Directions in Psychological Science, 12(4), 105-109.

Coleman, J. S. (1990). Foundations of social theory. Cambridge, MA: Harvard University Press.

Dunkel, A. (2011). Micro-cultural differences in Switzerland: The effectiveness of targeted promotional messages in the field of organ donation. Dissertation submitted to the Faculty of Communication Sciences, Università della Svizzera Italiana. https://doc.rero.ch/record/29382/files/2011COM006 .pdf.

Elman, C. (2005). Explanatory typologies in qualitative studies of international politics. International Organization, 59(2), 293-326.

Engeli, I., Green-Pedersen, C., \& Larsen, L. T. (2013). The puzzle of permissiveness: Understanding policy processes concerning morality issues. Journal of European Public Policy, 20(3), 335-352.

Engeli, I., \& Varone, F. (2011). Governing morality issues through procedural policies. Swiss Political Science Review, 17(3), 239-258.

Engeli, I., \& Varone, F. (2012). Morality politics in Switzerland: Politicization through Direct Democracy. In I. Engeli, C. Green-Pedersen, \& L. T. Larsen (Eds.), Morality politics in Western Europe: Parties, agendas and policy choices (pp. 88-113). New York: Palgrave Macmillan.

Euchner, E.-M., Heichel, S., Nebel, K., \& Raschzok, A. (2013). From 'morality' policy to 'normal' policy: Framing of drug consumption and gambling in Germany and the Netherlands and their regulatory consequences. Journal of European Public Policy, 20(3), 372-389.

Eurobarometer. (2007). Europeans and organ donation. Special Eurobarometer on organ donation. http://ec.europa.eu/public_opinion/archives/ebs/ebs_272d_en.pdf.

Flückiger, A. (2010). Emouvoir et persuader pour promouvoir le don d'organes? L'efficacité entre éthique et droit. Geneva, Zurich and Basel: Schulthess.

Gofen, A. (2015). Reconciling policy dissonance: Patterns of governmental response to policy noncompliance. Policy Sciences, 48(1), 3-24.

Grimmelikhuijsen, S., Jilke, S., Olsen, A. L., \& Tummers, L. (2017). Behavioral public administration: Combining insights from public administration and psychology. Public Administration Review, $77(1), 45-56$.

Hood, C. (2007). Intellectual obsolescence and intellectual makeovers: Reflections on the tools of government after two decades. Governance, 20(1), 127-144.

Howlett, M. (2009). Governance modes, policy regimes and operational plans: A multi-level nested model of policy instrument choice and policy design. Policy Sciences, 42(1), 73-89. 
Howlett, M. (2016). Policy tools \& their targets: Beyond nudges and utility maximization in policy compliance. Paper presented at the annual congress of the International Political Science Association, Poznan, 23.-28.7.

Howlett, M., \& Cashore, B. (2009). The dependent variable problem in the study of policy change: Understanding policy change as a methodological problem. Journal of Comparative Policy Analysis, 11(1), 33-46.

Howlett, M., \& Rayner, J. (2007). Design principles for policy mixes: Cohesion and coherence in 'new governance arrangements'. Policy and Society, 26(4), 1-18.

John, P. (2016). Behavioral approaches: How nudges lead to more intelligent policy design. In B. G. Peters \& P. Zittoun (Eds.), Contemporary approaches to public policy (pp. 113-131). UK: Palgrave Macmillan.

John, P., Cotterill, S., Moseley, A., Richardson, L., Smith, G., Stoker, G., et al. (2011). Nudge, nudge, think, think: Using experiments to change civic behavior. London: Bloomsbury Academic.

Johnson, E. J., \& Goldstein, D. G. (2003). Do defaults save lives? Science, 302, 1338-1339.

Johnson, E. J., Steffel, M., \& Goldstein, D. G. (2005). Making better decisions: From measuring to constructing preferences. Health Psychology, 24(4S), S17-S22.

Jordan, A., Wurzel, R. K. W., \& Zito, A. (2005). The rise of 'new' policy instruments in comparative perspective: Has governance eclipsed government? Political Studies, 53(3), 477-496.

Kahneman, D., \& Tversky, A. (2000). Choices, values and frames. Cambridge: Cambridge University Press.

Knill, C., Adam, C., \& Hurka, S. (2015). On the road to permissiveness? Change and covergence of moral regulation in Europe. Oxford: Oxford University Press.

Knill, C., Schulze, K., \& Tosun, J. (2012). Regulatory policy outputs and impacts: Exploring a complex relationship. Regulation \& Governance, 6(4), 427-444.

Knoepfel, P., Larrue, C., Varone, F., \& Hill, M. (2011). Public policy analysis. Bristol: Policy Press.

Lascoumes, P., \& Le Galès, P. (2007). Introduction: understanding public policy through its instrumentsFrom the nature of instruments to the sociology of public policy instrumentation. Governance, 20(1), $1-21$.

Levi-Faur, D. (2006). A question of size? A heuristics for stepwise comparative research design. In B. Rihoux \& H. Grimm (Eds.), Innovative comparative methods for policy analysis (pp. 43-66). New York: Springer.

Levin, I. P., Schneider, S. L., \& Gaeth, G. J. (1998). All frames are not created equal: A typology and critical analysis of framing effects. Organizational Behavior and Human Decision Processes, 76(2), 149-188.

Lipsky, M. (1980/2010). Street-level bureaucracy: Dilemmas of the individual in public services. New York: Russell Sage.

Maio, G., \& Haddock, G. (2009). The psychology of attitudes and attitude change. London: Sage.

Manatschal, A., \& Thomann, E. (2011). Vergleich des Organspendewesens in der Schweiz und Spanien. Bern: Study mandated by the Swiss Federal Office of Public Health, Institute of Political Science and Büro Vatter AG.

Matesanz, R. (2008). El Modelo Español de Coordinación y Trasplantes. Madrid: Aula Médica Ediciones.

Matesanz, R., \& Dominquez-Gil, B. (2007). Strategies to optimize deceased organ donation. Transplantation Reviews, 21(4), 177-188.

Matland, R. E. (1995). Synthesizing the implementation literature: The ambiguity-conflict model of policy implementation. Journal of Public Administration Research and Theory, 5(2), 145-174.

Mooney, C. Z. (1999). The politics of morality policy. Policy Studies Journal, 27(4), 675-680.

Mossialos, E., Costa-Font, J., \& Rudisill, C. (2008). Does organ donation legislation affect individuals' willingness to donate their own or their relative's organs? Evidence from European Union survey data. BMC Health Services Research, 8(1), 48.

Nelson, T. E., Oxley, Z. M., \& Clawson, R. A. (1997). Toward a psychology of framing effects. Political Behavior, 19(3), 221-246.

Newton, J. D. (2011). How does the general public view posthumous organ donation? A meta-synthesis of the qualitative literature. BMC Public Health, 11(1), 791-801.

Oliver, A. (2013). From nudging to budging: Using behavioural economics to inform public sector policy. Journal of Social Policy, 42(4), 685-700.

Oliver, A. (2015). Nudging, shoving, and budging: Behavioural economic-informed policy. Public Administration. https://doi.org/10.1111/padm.12165.

Organización Nacional de Trasplantes (ONT). (2009). Programa de garantía de calidad delproceso de donación. Memoria de resultados de la autoevaluación año 2009. Madrid: ONT.

Quigley, M., Brazier, M., Chadwick, R., Navarro, M., \& Paredes, D. (2008). The organ crisis and the Spanish model: Theoretical versus pragmatic considerations. Journal of Medical Ethics, 34(4), 223-224. 
Radecki, C. M., \& Jaccard, J. (1999). Signing an organ donation letter: The prediction of behavior from behavioral intentions. Journal of Applied Social Psychology, 29(9), 1833-1853.

Rithalia, A., McDaid, C., Suekarran, S., Norman, G., Myers, L., \& Sowden, A. (2009). Impact of presumed consent for organ donation on donation rates: A systematic review. British Medical Journal. https:// doi.org/10.1136/bmj.a3162.

Roels, L., Spaight, C., Smits, J., \& Cohen, B. (2010). Critical care staffs' attitudes, confidence levels and educational needs correlate with countries' donation rates: Data from the Donor Action database. Transplant International, 23(8), 842-850.

Sager, F. (2009). Governance and coercion. Political Studies, 57(3), 537-558.

Schaffrin, A., Sewerin, S., \& Seubert, S. (2015). Toward a comparative measure of climate policy output. Policy Studies Journal, 43(2), 257-282.

Schneider, A., \& Ingram, H. (1990). Behavioral assumptions of policy tools. The Journal of Politics, 52(2), 510-529.

Schulz, P. J., Nakamoto, K., Brinberg, D., \& Haes, J. (2006). More than nation and knowledge: Cultural micro-diversity and organ donation in Switzerland. Patient Education and Counseling, 64, 294-302.

Shafer, T. J., Wagner, D., Chessare, J., Zampiello, F. A., McBride, V., \& Perdue, J. (2006). Organ donation breakthrough collaborative. Increasing organ donation through system redesign. Critical Care Nurse, 26(2), 33-48.

Shafir, E. (2013). The behavioral foundations of public policy. Princeton, NJ: Princeton University Press.

Simillis, C. (2010). Do we need to change the legislation to a system of presumed consent to address organ shortage? Medicine, Science and the Law, 50(2), 84-94.

Siminoff, L. A., Gordon, N., Hewlett, J., \& Arnold, R. M. (2001). Factors influencing families' consent for donation of solid organs for transplantation. JAMA, 286(1), 71-77.

Simpkin, A. L., Robertson, L. C., Barber, V. S., \& Young, J. D. (2009). Modifiable factors influencing relatives' decision to offer organ donation: Systematic review. British Medical Journal. https://doi. org/10.1136/bmj.b991.

Studlar, D. T., \& Burns, G. J. (2015). Toward the permissive society? Morality policy agendas and policy directions in Western democracies. Policy Sciences, 48(3), 273-291.

Swisstransplant. (2008). Jahresbericht 2008. Bern: Swisstransplant.

Swisstransplant. (2009). Jahresbericht 2009. Bern: Swisstransplant.

Thaler, R. H., \& Sunstein, C. R. (2008). Nudge: Improving decisions about health, wealth, and happiness. Newhaven: Yale University Press.

Thomann, E. (2018). Customized implementation of European Union food safety policy: United in diversity? Palgrave Macmillan.

Thomann, E., \& Manatschal, A. (2016). Identifying context and cause in small-N settings: A comparative multilevel analysis. Policy Sciences, 49(3), 335-348.

Thomann, E., \& Zhelyazkova, A. (2017). Moving beyond (non-)compliance: The customization of European Union policies in 27 countries. Journal of European Public Policy, 24(9), 1269-1288.

Van der Heijden, J., \& Kosters, M. (2015). From mechanism to virtue: Evaluating nudge-theory. Evaluation, 21(3), 276-291.

Vedung, E. O. (1998). Policy instruments: Typologies and theories. In M.-L. Bemelmans-Videc, R. C. Rist, \& E. O. Vedung (Eds.), Carrots, sticks and sermons: Policy instruments and their evaluation (pp. 21-58). New Brunswick and London: Transaction Publishers.

Weaver, R. K. (2014). Compliance regimes and barriers to behavioral change. Governance, 27(2), 243-265. 